\title{
Literatura infanto-juvenil e ciências: convergência e desafios para o mercado editorial brasileiro
}

\author{
Glaucio Aranha \\ Universidade Federal do Rio de Janeiro (Rio de Janeiro, Brasil)
}

\begin{abstract}
RESUMO: TRATA DA FORMAÇÃO DE NOVOS NICHOS MERCADOLÓGICOS DA INDÚSTRIA EDITORIAL, COM FOCO NA CONVERGÊNCIA ENTRE OS CAMPOS DA LITERATURA E DAS CIÊNCIAS. APÓS BREVE CONTEXTUALIZAÇÃO DO FENÔMENO, APRESENTA UMA ANÁLISE COMPARATIVA DE DUAS OBRAS DE LITERATURA INFANTOJUVENIL QUE BUSCAM A IMBRICAÇÃO ENTRE OS CAMPOS CITADOS, SENDO UMA NORTE-AMERICANA E OUTRA BRASILEIRA. A ABORDAGEM SEGUE UMA ORIENTAÇÃO EXPLORATÓRIA ALIADA À PERSPECTIVA FENOMENOLÓGICA. BUSCA PROMOVER A IDENTIFICAÇÃO DOS PRINCIPAIS DESAFIOS A SEREM OBSERVADOS POR AUTORES E EDITORES DO SEGMENTO.
\end{abstract}

ABSTRACT: THIS ESSAY EXPLORES NEW MARKETS FOR PUBLISHING INDUSTRY, FOCUSING THE CONVERGENCE BETWEEN THE LITERATURE AND SCIENCE FIELDS. IT PRESENTS A COMPARATIVE ANALYSIS OF TWO WORKS OF LITERATURE FOR CHILDREN WHO SEEK THE OVERLAP BETWEEN THE FIELDS MENTIONED, BEING AN AMERICAN AND A BRAZILIAN STORIES. THE APPROACH FOLLOWS AN EXPLORATORY ORIENTATION COMBINED WITH A PHENOMENOLOGICAL PERSPECTIVE. IT SEEKS TO PROMOTE THE IDENTIFICATION OF THE MAIN CHALLENGES TO BE EXPLORED BY AUTHORS AND PUBLISHERS OF THIS SEGMENT.

PALAVRAS-CHAVE: LITERATURA INFANTO-JUVENIL, CIÊNCIAS, MERCADO.

KEYWORDS: CHILDREN'S LITERATURE, SCIENCE, PUBLISHING. 
indústria cultural traz em si a lógica capitalista, marcada pelo impulso de (re) criar necessidades e espaços de consumo. As prateleiras das livrarias, frequentemente, ofertam ondas de produtos para "novos" nichos. Nos últimos anos, por exemplo, é possível verificar os fenômenos de vendas em torno de livros sobre o mundo árabe, religião muçulmana e outros aspectos impulsionados pelos conflitos no Oriente Médio; "bruxaria" e mundos fantásticos para o público infanto-juvenil, motivados pela série Harry Potter; e, mais recentemente, livros sobre vampiros, catapultados pela série da autora Stephenie Meyer; dentre outros.

No presente ensaio, proponho uma reflexão acerca de um destes "novos" nichos, recortando o fenômeno da crescente publicação de obras de literatura infanto-juvenil (LIJ) que buscam a imbricação entre os campos da literatura e da ciência. Não interessa aqui a perspectiva mercadológica, política ou ética do motor que alimenta e realimenta o fluxo das produções textuais contemporâneas, mas, sim, apresentar uma abordagem exploratória de base fenomenológica.

Neste sentido, apresenta, inicialmente, breves considerações acerca do discurso científico e literário, problematizando as fronteiras narrativas em relação à indústria cultural. Após, discute a produção brasileira de narrativas infanto-juvenis que busca reconectar ciência e literatura.

\section{II}

A pesquisadora Ana Maria Sánchez Mora (2003) demonstra que ao longo da história é possível verificar numerosos casos de convergência entre a literatura e a divulgação científica. Revela diversos pontos desta intersecção que abrangem publicações de narrativas autobiográficas a romances produzidos por autores-cientistas como: Albert Einstein, George Gamow, J. B. S. Haldane, Stephen Jay Gould, Carl Sagan, Nick Calder, Paul Davies, Primo Levi, Oliver Sacks, Isaac Asimov, Martin Gardner e outros. Mora defende a tese de que a ciência, na qualidade de produto cultural, é acima de tudo uma construção narrativa. Avançando neste sentido, proponho pensarmos o conheci- 
mento científico como um discurso narrativo que investe esforços radicais na busca da verossimilhança.

Mora destaca o modo como, até o século XIX, as fronteiras entre a escrita filosófica, literária e científica não eram demarcadas como hodiernamente. $\mathrm{Na}$ época, formavam um só corpus envolto por uma filosofia natural. Podemos observar, principalmente após o início do século XX, que o discurso científico investiu cada vez mais na busca de um espaço discursivo singular. Tal busca da autonomia de seu discurso culminou cada vez mais na "esterilização" dos aspectos conotativos da linguagem, destilando a função referencial até o maior grau de pureza possível, em relação aos demais discursos. Em certa medida, este trajeto guarda similaridades com a própria busca de autonomia do campo da literatura, no sentido de decantar e destilar o fundamento último de sua arte, a literariedade: uma corrida alquímica pelo ouro, pela construção de critérios discursivos que validassem um cânone, distanciandose da linguagem cotidiana.

Neste caminho, o discurso científico investiu na refutação do caráter ficcional, cercando-se de técnicas que buscavam respaldar as "verdades provisórias" de suas narrativas, emprestando-lhes ares de "Verdade" por meio da estruturação lógico-formal do seu discurso. Curioso notar que muitos dos estudos da literatura, focados na questão da autonomia, buscavam a valorização da natureza técnica da obra - literatura como sistema, especialmente entre os formalistas e estruturalistas, distanciando o discurso literário do cotidiano. A função poética evidencia-se, assim, como abrigo para recortes, métodos e experimentações próprias de cada autor.

Robert Fullford (1999) destaca o modo como o fazer literário surgiu e retornou para a esfera da experiência. Aborda a natureza narrativa dos boatos e seu poder criativo, bem como o modo como esta textualidade emerge da experiência, desloca-se do contexto (recorte), constituindo uma estória para reingressar no campo da experiência (aplicação) em um processo de contínua experimentação.

O movimento de alguns autores no sentido de trabalhar na fronteira entre o científico e o literário aponta para a ocupação de uma região de embaçamento do conhecimento superespecializado. Tal fato não deve ser confundido com a criação de adaptações de conteúdos com caráter pedagógico, mas como uma proposta estética de uso do conhecimento científico como 
matéria prima para o fazer literário, gerando obras em que este conhecimento é indispensável para a compreensão da narrativa. Não se trata de construir uma ponte entre o mundo da ciência e o da literatura, mas de praticar a ponte. Trata-se de usar o conhecimento científico como possibilidade para o discurso poético. Experiência esta que, em certa medida, já atravessava a poética científica da Escola de Recife. As poesias de Silvio Romero, Rocha Lima, Martins Júnior são marcadas pela temática e linguagem científica, bem como a de Augusto dos Anjos.

Mora (2003) propõe reintegrar o campo da cultura científica através da reaproximação com o literário. Neste sentido, verificam-se frutíferas experiências tanto em prosa, quanto em dramaturgia. No campo da prosa, as obras de Leopoldo de Méis, O outro lado da ciência e O outro lado da ciência vol. 2: contos e crônicas de cientistas brasileiros, acompanham uma tendência da indústria cultural internacional de publicação de obras de autores-cientistas como Irvin Yalom (Quando Nietzsche chorou e A cura de Schopenhauer), Oliver Sacks (Tempo de despertar e Um antropólogo em Marte), V. S. Ramachandran (Fantasmas no cérebro), dentre outros. No campo da dramaturgia, temos montagens como $O$ método cientifico: como o saber mudou a vida do homem, de Leopoldo de Méis e Diucênio Rangel; $A$ estrela da manhã, de Calixto de Inhamuns; Da Vinci pintando o sete, de Francisco Alves; Copenhagen, de Michael Frayn; e, Einstein, de Gabriel Emanuel.

Cecilia Galvão (2006) aponta possíveis caminhos para a exploração desta convergência a partir da identificação: da ciência narrativa; das culturas em confronto, em interação ou em complemento; da dimensão social e literária, discutindo os benefícios dos conceitos científicos; da busca sobre os ganhos de uma visão multidimensional e complexa da cultura; e, da busca sobre o modo como a subjetividade atravessa a análise e se cruza com a objetividade da ciência.

As direções apontadas por Galvão vão ao encontro da reflexão de Edgar Morin (1991), quando, tratando do pensamento complexo, analisa o processo de desenvolvimento dos pensamentos científico e literário. Morin observa que o antagonismo guarda em si a complementaridade, que os discursos se interpenetram indissociavelmente. A ciência é vista assim como mais uma possibilidade discursiva amalgamada a tantas outras na complexa rede do conhecimento humano; não devendo este "amálgama” ser antagonizado. 


\section{III}

A aproximação entre o discurso científico e literário não é novidade, ou melhor, pode ser considerada mais uma das "velhas novidades" que nos são apresentadas a cada temporada de saturação e recomposição do mercado. A ascensão da ciência moderna impactou sobre o imaginário de muitos escritores estimulando, já no século XVIII, a criação de narrativas sobre viagens a outros planetas, criação de seres fantásticos e outros. A ciência e o literário começavam a dialogar, ainda que timidamente, turvando a rigidez de suas fronteiras. Podem ser considerados marcos deste processo, obras como: Micromégas, de Voltaire, lançada em 1752, que tratava da jornada espacial de um gigante que resolve se aventurar pelo universo; As viagens de Gulliver, romance satírico escrito por Jonathan Swift, publicado em 1726 (alterado em 1735), em cuja terceira parte trata da Ilha Flutuante de Laputa, momento em que critica o pensamento científico e sua capacidade de contribuir positivamente para o desenvolvimento da humanidade; e, Frankenstein ou o moderno Prometeu, de Mary Shelley, romance de terror gótico, com fortes marcas românticas, publicado em 1818 (alterado na terceira edição de 1831), que conta a história do estudante de ciências naturais, Victor Frankenstein, e seus esforços para criar um ser vivo em laboratório. Por certo, a lista poderia ser alongada, mas basta aqui apontar alguns dos marcos.

Durante o século XIX, outros tantos autores, como Edgar Allan Poe, Nathaniel Hawthorne e Fitz-James O'Brien criaram narrativas impregnadas pelo imaginário científico. Entretanto, foi apenas no final do século XIX que ganhou maior evidência, nas mãos de Júlio Verne, o que se convencionou chamar de fição científica, delimitando de vez um nicho para certa produção literária. Nos romances de Verne, o conhecimento científico passou a ocupar um nível primário em relação ao tema das narrativas. Orientação científica encontrada também nas novelas de H. G. Wells.

No Brasil, a produção de ficção científica é pequena em termos editoriais. Vale destacar obras como Três meses no século 81 e $A$ cidade perdida, de Jerônymo Monteiro; Eles herdarão a Terra, de Dinah Silveira de Queiroz; Quintessência, de Flavio Medeiros; e, mais recentemente, autores da terceira geração como Ludimila Hashimoto, Romeu Martins e Marcelo Jacinto Ribeiro.

Vale destacar, entretanto, que o discurso científico encontra-se presente na Literatura não apenas em obras de caráter ficcional. Nos relatos de viagem 
do século XVIII e século XIX, é possível verificar a presença de dois tipos de discurso, sendo um deles marcado pelo subjetivismo (impressões pessoais do viajante) e outro pelo objetivismo (próximo ao discurso científico), (PLATT, 1999). Como exemplo desta última tendência, podemos evocar a obra Viagem pelas provincias do Rio de Janeiro e Minas Gerais, de Auguste de SaintHilaire, na qual o autor descreve sua passagem por municípios brasileiros. Já no início, informa ao leitor que o escopo da narrativa é servir à ciência. Mary Louise Platt destaca que o discurso científico impactava sobre estas narrativas, emprestando ao discurso literário certa impessoalidade: "nos escritores posteriores de viagens científicas, o sensacionalismo e a escravidão desaparecem, como desaparece a maior parte dos dramas sociais de qualquer espécie" (PLATT, 1999, p. 94).

No contínuo deste enamorar que remonta a longa data, observamos mais recentemente no mercado editorial o surgimento de obras de ficção escritas por cientistas e que apresentam o conhecimento científico e/ou prática da pesquisa científica como leitmotiv da narrativa.

\section{IV}

A indústria editorial brasileira tem investido na publicação de narrativas destinadas ao público infanto-juvenil que dialogam com o campo de ciências, por exemplo, a Coleção Lelé da Cuca, com os títulos $A$ bistória da ameba (2002a) e $A$ bistória do plâncton (2002b), de Jack Robb e Bernie Stringle (Ática); Tem um cabelo na minha terra!: uma história de minhoca (2002), de Gary Larson (Cia. das Letrinhas); Blusa listrada com calca florida (2010), de Barbara Schnurbush (Artmed), dentre outros. Entre os autores brasileiros temos: Memórias de um virus (2002), de Luiz Claudio Cardoso (Scipione), Cartas marcadas: uma bistória de amor entre iguais (2007), de Antônio Gil Neto e Edson Gabriel Garcia (Cortez), a série As aventuras de um neurônio lembrador (2005a, 2005b, 2005 c, 2005d, 2005e), de Roberto Lent (Vieira e Lent), dentre outros.

A leitura comparativa das narrativas supra referidas permite visualizar algumas tendências e obstáculos a serem superados, principalmente, pela produção brasileira. Tomarei aqui, brevemente, dentre as obras citadas dois casos que sumarizam as diferenças entre estes textos, a saber: Blusa listrada com calça 
florida (2010), de Barbara Schnurbush, e O neurônio apaixonado (2005a), de Roberto Lent.

O livro de Barbara Schnurbush, escrito em primeira pessoa, com ilustrações de Cary Pillo, narra a estória de Lili, uma menina cuja avó (Naná) está sendo acometida pela doença de Alzheimer. A narrativa parte da observação da menina em relação às mudanças comportamentais da avó, que tinha o hábito de ler histórias para a neta, além de outras atividades que praticavam juntas como colorir desenhos, cultivar o jardim e alimentar os pássaros. Ao longo do texto, Lili percebe que a avó começa a esquecer certas palavras, confundir o nome dos pássaros que até então dominava e ensinava à neta. Pelo olhar infantil, a avó começa a ser vista não como portadora de uma doença, mas como uma pessoa querida que começa a passar por transformações em seu modo de ser e agir. O gatilho para a consciência acerca do Alzheimer surge quando Lili ouve o comentário de sua mãe sobre a estranha combinação de roupas da avó, qual seja, blusa listrada com calça florida. É o momento em que a mudança de comportamento se torna mais nítida para a família. Sem romper o pacto de leitura e sem impor a narrativa o discurso científico ou pedagógico, dobra-se o mundo diegético sobre o mal de Alzheimer pelos olhos da protagonista. O estado degenerativo de Naná surge na observação da neta como um processo de aproximação e identificação. Lili não vê problemas nas combinações de roupas da avó, pois reconhece nestas o seu próprio gosto por cores. O olhar de Lili se distancia do olhar dos pais, mais apegados ao status quo ante. Para a menina, se antes estava na condição de aprendiz em relação à avó, agora passa paulatinamente à condição de mentora. A relação entre ambas é renovada pelas transformações comportamentais e as implicações sociais da doença são delegadas à apreciação da protagonista.

Para contraposição com textos brasileiros, tomo a série $A s$ aventuras de um neurônio lembrador, de Roberto Lent, a qual é composta por cinco livros: $O$ neurônio apaixonado (LENT, 2005a), O mico do neurônio escutador (LENT, 2005b), Um neurônio de olho vivo (LENT, 2005c), Atenção, neurônios na bicicleta! (LENT, 2005d) e O esquecimento do neurônio lembrador (LENT, 2005e). Todos os cinco livros contam com a ilustração de Flavio de Almeida, usando traço cartunesco para humanizar o desenho esquemático clássico de uma célula neuronal com seus axônios, núcleo e dendritos. A narrativa é feita em terceira pessoa e o autor, desde o início, apresenta-se diretamente ao leitor na condição de 
neurocientista e narrador do que vai se seguir. A narrativa acontece em dois planos: o ambiente cotidiano de ruas, casa e escola, em que atua o personagem Ptix, e o interior do corpo de Ptix, em que atua o neurônio Zé Neurim e demais neurônios e células.

Para a presente análise, tomarei apenas um dos títulos da série, valendo destacar que as observações técnicas atravessam todos os demais títulos. Em O neurônio apaixonado (LENT, 2005a), é narrada a estória do personagem Zé Neurim, um neurônio que habita o cérebro de Pedro (apelidado de Ptix), um menino de nove anos.

O protagonista é confrontado com situações geradas pela paixão de Ptix por Camila. O enredo tem início quando Ptix vê Camila pela primeira vez, e dentro de si todas as engrenagens neurológicas se agitam. Ptix e Camila são apenas pano de fundo para a própria sintomatologia da paixão: “(...) foi como se tivesse sido enfeitiçado: parou e ficou plantado como uma árvore. A boca abriu, mas não disse uma palavra. E o coração disparou descontrolado (...)".

Zé Neurim se vê diante de reações físicas inéditas para ele e seguindo a trajetória do herói parte em busca da compreensão (solução) dos processos emocionais envolvidos, sendo estes o campo de ação da narrativa. Ele dispara mensagens pela rede neural na esperança de compreender o distúrbio causador da situação de desequilíbrio orgânico. O neurônio inicia a busca (herói buscador) por informações sobre o fenômeno. $\mathrm{O}$ narrador interfere no fluxo diegético, fornecendo informações complementares sobre os processos científicos implicados. A jornada de Zé Neurim toma a forma de troca de informações sinápticas com a rede neural de Ptix. Surgem como personagens secundários outros neurônios (Ocipitaldo Luzes, do setor de Cores e Sombras; Olívio Gravador, do setor de Sons e Chiados) com o intuito de colaborar para a compreensão dos fatos, mas é no encontro com Acumbente dos Prazeres, o neurônio apaixonado, que Zé Neurim encontrará o que Propp (1984) denomina como função do doador do "objeto mágico" que contribuirá para a solução da questão. No caso, o objeto é uma informação. Acumbente revela para o protagonista: "Não pude me controlar, e saí cantando, falando alto, mandando mensagens para vários locais do cérebro do Ptix. Depois, quando acalmei, não entendi o que tinha acontecido".

O fluxo narrativo é, então, interrompido bruscamente pela pergunta do narrador acerca de quais foram os motivos que levaram à desordem orgânica de Ptix. Neste momento, o narrador evoca, como deus ex machina, a figura 
de um colega de trabalho, o qual é apresentado ao leitor, através de uma fotografia da pessoa referida como "colega de trabalho" (a autor e o narrador se confundem), rompendo a continuidade narrativa. Nitidamente orientado para o pedagogismo, em relação ao conteúdo científico, a narrativa perde sua finalização. O enredo é interrompido em favor da explicação técnica, comprometendo o pacto de leitura. Com isto, observa-se o esvaziamento da função estética (função poética) em face da função referencial imposta ao texto, comprometendo a literariedade. A diegese é, igualmente, sacrificada uma vez que o discurso científico formal esteriliza o constructo literário.

A pungente intervenção do narrador/autor é bastante evidente na obra de Roberto Lent, razão pela qual foi escolhida com o intuito de contrastar, com outra obra em que o pacto narrativo, a função poética, o caráter mimético e a diegese são mais adequadamente tratados. Vale ressaltar que este problema estrutural atravessa muitos outros textos que buscam ocupar a fronteira entre o discurso científico e o literário para o público infanto-juvenil, servindo como alerta para o desafio técnico que precisa ser vencido na produção textual brasileira que assume o escopo de ser simultaneamente uma obra científico-pedagógica e literária.

A construção narrativa demanda especificidades que vão além da intencionalidade daqueles que produzem uma escritura. O texto literário pode dialogar com o campo das ciências, tendo nestas a função referencial como sua segunda dominância, ${ }^{1}$ todavia, a função poética não pode, nem deve ser deslocada da primeira dominância, sob pena de se descaracterizar a obra em relação à sua qualidade literária.

Apesar da ampliação do mercado de literatura infanto-juvenil que procura estabelecer-se em sintonia com o discurso e universo científico, observa-se que o preparo técnico para lidar com ambas as esferas ainda precisa ser alvo

1. O conceito de "dominante", formulado por Roman Jakobson, deve ser compreendido como o centro gravitacional que regulamenta, determina e transforma os componentes da obra artística (JAKOBSON, 1983, p. 485). 
de aprofundamentos. No Brasil, é crescente o número de trabalhos acadêmicos que destacam a carência desta área e a necessidade de fomentar este diálogo (LINSINGEN, 2008, 2009; RABE et al., 2010; LOPES e SALOMÃO, 2009), mas a capacitação técnica é basilar para qualquer campo, representando um dos mais árduos desafios: o deslocamento de áreas de conforto em propostas que buscam ocupar espaços de fronteira.

\section{Referências bibliográficas}

CARDOSO, Luiz Claudio. Memórias de um vírus. São Paulo: Scipione, 2002.

FULLFORD, Robert. The triumph of narrative: storytelling in the age of mass culture. Toronto: Anansi, 1999.

GALVÃO, Cecilia. Ciência na literatura e literatura na ciência. Interacções, n. 3, p. 32-51, 2006. Disponível em: <http://www.eses.pt/interaccoes>.

LARSON, Gary. Tem um cabelo na minha terra!: uma história de minhoca. São Paulo: Companhia das Letrinhas, 2002.

LENT, Roberto. Atenção, neurônios na bicicleta! Rio de Janeiro: Vieira \& Lent, 2005d.

LENT, Roberto. O esquecimento do neurônio lembrador. Rio de Janeiro: Vieira \& Lent, 2005e.

LENT, Roberto. O mico do neurônio escutador. Rio de Janeiro: Vieira \& Lent, 2005b.

LENT, Roberto. O neurônio apaixonado. Rio de Janeiro: Vieira \& Lent, 2005a.

LENT, Roberto. Um neurônio de olho vivo. Rio de Janeiro: Vieira \& Lent, 2005c.

LINSINGEN, Luana von. Literatura infantil no ensino de ciências: articulações a partir da análise de uma coleção de livros. Dissertação (Mestrado). 121 p. Programa de PósGraduação em Educação Científica e Tecnológica, Universidade Federal de Santa Catarina, Florianópolis, 2008.

LINSINGEN, Luana von. A literatura infanto-juvenil e o ensino de ciências: uma relação possível. Anais do $4^{\circ}$ SLIJSC. In: DEBUS, Eliane; RAUEN, Fábio José; LOPES, Elinia Medeiros, SALOMÃO, Simone Rocha. O uso da literatura no ensino de ciências no primeiro segmento do ensino fundamental: desafios e possibilidades. Anais do VIII ENPEC - Encontro Nacional de Pesquisa em Educação em Ciências. Florianópolis, 08 de novembro de 2009. Disponível em <http://www.foco.fae. ufmg.br/pdfs/340.pdf>. Acesso em 13/04/2011.

MORA, Ana María Sánchez. A divulgậão da Ciência como Literatura. Rio de Janeiro: Casa da Ciência e Editora UFRJ, 2003.

NETO, Antônio Gil et GARCIA, Edson Gabriel. Cartas marcadas: uma história de amor entre iguais. São Paulo: Cortez, 2007. 
PLATT, Mary Louise. Os olhos do império: relatos de viagem e transculturação. Bauru: EDUSC, 1999.

PROPP, Vladimir Iakovlevich. Morfologia do conto maravilhoso. Rio de Janeiro: Forense Universitária, 1984.

RABE, Marcia Maria King; LIMA, Silmara; CARLETTO, Marcia Regina. O uso da literatura infantil no ensino de ciências na educação infantil. II Simpósio Nacional de Ensino de Ciência e Tecnologia, 07 a 09 de outubro de 2010. Acesso em 13 de abril de 2010. Disponível em < http:/ / www.pg.utfpr.edu.br/sinect/anais2010/artigos/Ens_ Cien_SI/art153.pdf>.

ROBB, Jack et STRINGLE, Bernie. A história da ameba. São Paulo: Ática, 2002a. (Coleção Lelé da Cuca)

ROBB, Jack et STRINGLE, Bernie. A bistória do plâncton. São Paulo: Ática, 2002b. (Coleção Lelé da Cuca)

SCHNURBUSH, Barbara. Blusa listrada com calça florida. Porto Alegre: Artmed, 2010.

Recebido em 04 de maio e aprovado em 19 de maio de 2011. 